Vocal instability over time in individual male European Nightjars,

Caprimulgus europaeus: recommendations for acoustic monitoring and surveys.

Sarah Raymond ${ }^{* 1}$, Sarah Spotswood*1, Hazel Clarke ${ }^{1}$, Natalia Zielonka ${ }^{1}$, Andrew Lowe ${ }^{2}$ and Kate L. Durrant ${ }^{\dagger 1}$.

* Joint first authors

† kate.durrant@nottingham.ac.uk

1. The University of Nottingham, School of Life Sciences, University Park, Nottingham, NG7 2RD, United Kingdom.

2. Birklands Ringing Group, 159 Sherwood Street, Warsop, Mansfield, NG20 0JX, United Kingdom.

Word count: 5210

Running Head: Vocal discrimination in nightjars 


\section{Vocal instability over time in individual male European Nightjars, Caprimulgus europaeus: recommendations for acoustic monitoring and surveys.}

Acoustic monitoring of birds is developing rapidly as equipment, methods and analyses improve. However, most population monitoring studies still utilise traditional techniques like mark-recapture or line transects. Rebbeck et al. (2001) used vocal recordings of male European nightjars, Caprimulgus europaeus, to identify individuals, finding that four acoustic parameters correctly assigned $98.5 \%$ of calls to individuals. We tested Rebbeck et al.'s methods on a population of European nightjars recorded over two successive breeding seasons and found that percentage of males correctly classified within a season reached a maximum of $73.5 \%$, rising to $75 \%$ if full-length calls and 13 acoustic parameters were used. We tested whether males could be reidentified over a two-year period and found that only $20 \%$ of calls were assigned to the same putative territorial individuals, despite separate ringing data showing that males can maintain site fidelity for up to eight years. Our results indicate that the characteristics of male nightjar vocalisations may alter over time. We therefore recommend that vocal discrimination be used in conjunction with existing monitoring techniques when surveying for population monitoring, that as many call parameters as possible are used and that recording for automated presence/absence surveys takes place over a short time-frame.

Keywords: European nightjar, Caprimulgus europaeus, acoustic monitoring, vocal individuality, census method, discriminant function analysis

\section{Introduction}

Birds of many species use auditory cues to recognise other individuals (Halpin 1991). This ability to discriminate among different individuals is vital to the evolution of sociality and the maintenance of cooperative relationships in many taxa (Axelrod and Hamilton 1981; Colgan 1983). Vocal discrimination can be used for purposes such as neighbour-stranger discrimination (Falls 1982; Budka and Osiejuk 2013) or identification of mates and offspring (Charrier et al. 2001). Successful individual recognition using vocalisations requires low intra- and high inter-individual variation (Falls 1982). This type of individuality in acoustic 
signals has been identified to some degree in most bird species investigated so far (Peake et al. 1998; Terry et al. 2005; Grava et al. 2008; Li et al. 2017; Zdenek et al. 2017). A variety of temporal and frequency variables in calls have been shown to be useful in identifying individuals of different species (Charrier et al. 2001; Rebbeck et al. 2001; Grava et al. 2008; Klenova et al. 2011). Identification from vocalisations can provide a useful non-invasive means of monitoring birds that are normally difficult to observe (Terry et al. 2005).

Existing techniques for monitoring and tracking birds include the use of radio transmitters, satellite loggers, geolocators, coloured and numbered bands or tags, tattoos, dyes and medical cautery units, but these techniques are labour-intensive, costly and/or invasive, so usually limited to tracking only a few individuals (Budka et al. 2015). While tagging birds can provide accurate data on those individuals, extrapolation of data from tagged individuals to the whole population can also be inaccurate (Budka et al. 2015). Capture can also result in harmful disturbance to birds (McGregor and Peake 1998; Terry et al. 2005). Many existing techniques are unsuitable for difficult to observe species, such as nocturnal, crepuscular or secretive birds, or those sensitive to human disturbance (Terry et al. 2005). It is preferable to use naturally occurring markers of individuality which can be detected non-invasively, such as vocalisations, where possible (McGregor and Peake 1998; Budka et al. 2015). While all sampling techniques suffer from biases, the non-invasive nature of vocal identification reduces the biases associated with handling and physical marking (Terry et al. 2005). Acoustic census studies have been conducted in a variety of bird species, including the European bittern, Botaurus stellaris and black-throated divers, Gavia arctica (Gilbert et al. 1994), common cuckoo, Cuculus canorus (Li et al. 2017), the corncrake, Crex crex (Peake et al. 1998; Budka et al. 2015), the crested auklet, Aethia cristatella (Klenova et al. 2011), eagle owls, Bubo bubo (Lengagne 2001; Grava et al. 2008), and the European nightjar, Caprimulgus europaeus (Rebbeck et al. 2001). 
The European nightjar, hereafter referred to as the nightjar, is a crepuscular, migratory, insectivorous bird that breeds across most of the western Palearctic region and winters in southern and eastern Africa (Cramp 1985; del Hoyo et al. 1999). It is the only member of the Caprimulgidae native to the UK (Cresswell and Edwards 2013). Nightjars are ground-nesting and breed in areas of lowland heath, clearings, clear-fells and at the edges of woodland and forestry plantations (del Hoyo et al. 1999). The species has declined in both numbers and range in the UK since the late 19th century, due to long-term destruction and degradation of their heathland and woodland habitats and is listed on the Amber list of Birds of Conservation Concern in the UK (Cramp 1985; Langston et al. 2007; Eaton et al. 2015). Although nightjars are threatened, their ecology is still poorly understood (Lowe et al. 2014). It is critical to have the ability to conduct accurate nightjar censuses so that trends in population size and stability can be assessed (Jiguet and Williamson 2010).

Individual recognition of acoustic signals is particularly important for birds because it enables communication over a longer distance than visual cues (Vargas-Castro et al. 2017). The crepuscular nature of nightjars (Jiguet and Williamson 2010) is likely to limit how effectively they can distinguish among individuals visually, whereas, the clarity of vocalisations is unaffected by light levels. Birds can utilise the differences between the songs of potential mates to assess the 'quality' of an individual, with longer and higher-tempo songs being indicative of more experienced and better-quality birds in species such as the Java sparrow Lonchura oryzivora (Ota and Soma 2014). Acoustic recognition and the speciesspecific nature of calls also allow nightjars to identify threats and to alert conspecifics (Brandes 2008; Magrath et al. 2010) or to maintain territories (Parra et al. 2017).

Rebbeck et al. (2001) examined recognition of vocal individuality in nightjars by recording males 'churring', as the typical male territorial call is known, on 21 different territories between dusk and midnight throughout the breeding season. They reported that 
four parameters extracted from the male churring could be used to classify $98.5 \%$ of the individuals correctly using discriminant function analysis. Pulse rates alone were found to classify $95 \%$ of individuals correctly, with the major phrase pulse rate (Figure 1.) being the most useful variable for identifying individuals. Rebbeck et al. (2001) intended to assess return rates of males to the same territory; however, there were insufficient between-year data, which also prohibited analysis of longer-term vocal stability of individuals. Despite this, Rebbeck et al. (2001) suggested that individual discrimination of male nightjars by call was feasible and a potentially useful surveying tool. This technique has not been widely adopted in the intervening years even with improvements in both equipment, such as automated recording devices, and analysis software; perhaps due to the lack of conclusive evidence regarding the vocal stability of male nightjars. A large number of studies involving population monitoring still use techniques such as line transects and capture-mark-recapture (White and Burnham 1999) and assign individual males to territories based on behavioural cues alone (e.g. Tella et al. 2005; Gómez-Catasús et al. 2018).

The aim of this study was to test whether the method for identifying individuals (Rebbeck et al. 2001) is replicable, effective and applicable across years and to other populations of nightjars. This study recorded male nightjar churrs across a two-year period and investigated the use of pulse rates and phrase lengths (a discrete unit comprised of two or more adjacent pulses) as predictors of within-year individuality and between-year individual site fidelity. The study also tested whether limiting the number of parameters or the song length used in analysis affected the effectiveness of individual discrimination. Utilising the four parameters outlined in Rebbeck et al.'s (2001) study was predicted to produce a similar level of correct classifications in this study. We also predicted that increasing the number of call parameters used for individual identification would improve the percentage of calls correctly classified to individuals. 


\section{Materials and Methods}

\section{Study site}

The study was carried out in Sherwood Pines Forest Park, Nottinghamshire, UK (Latitude = 53.15, Longitude $=-1.08$ ), which has a 17 -year history of nightjar population monitoring (Lowe et al. 2014). Nightjars were recorded during their breeding season from May until August 2016 and 2017 on 11 different potential nightjar territories across the 1335 ha site. These locations were chosen on the basis of habitat suitability and where recordings had been made in the past. The territories varied in habitat-type but most consisted of a mix of commercial pine plantations, clear-fell, lowland heath and some deciduous trees (Lowe et al. 2014).

\section{Population monitoring}

Extensive efforts have been made to monitor nightjars at Sherwood Pines Forest Park over the last 17 years. Surveyors had detailed knowledge of the site and the nightjar population and their territories. The compact size of the park and ease of accessibility make this study site suitable for long-term monitoring. The number of males, pairs, nests and fledged chicks on every territory have been recorded each year since 2004 (e.g. Lowe et al. 2014), with nightjars regularly caught in mist-nets and ringed under licence from the British Trust for Ornithology. This allowed assessment of recapture rates and thus determination of whether male nightjars were returning to the same territories between different years. Because nightjars are difficult to catch and re-catch, and rings are impossible to observe adequately in the field for individual identification, the return rate data are limited, yet important and complementary to the present study.

The 11 territories were labelled as: 1, 6, 14a, 14b, 16, C, D, F, Fb, G and I. All male nightjars were recorded on at least two occasions at each territory within a single year, with 
all but sites 1, 16 and $\mathrm{C}$ being recorded on three nights - these three territories were abandoned by the nightjars prior to the third visit.

A Sennheiser MKH 70 microphone in a Sennheiser MZW 70-1 basket windshield and Sennheiser MZH 70-1 long-hair wind muff attached to a Marantz Professional Solid-State Recorder PMD660 was used to record nightjar churrs in the field. Recording began shortly after civil twilight, the time when the geometric centre of the Sun's disk is at most 6 degrees below the horizon, when nightjars emerged for the night (Cadbury 1981) and continued until the male stopped churring and flew off to forage. It was assumed that the initial calls of the evening heard at each site belonged to the territorial male at that site. Birds heard later in the evening, after the initial churring period, could not be determined to be the same territorial male and were discounted. All birds were simultaneously observed by a second fieldworker who noted spatial positions and behaviours. Recording stopped if more than one male, distinguished from females by large white spots on the wings and tail, was observed at the same time on the same territory, because it was unclear which male was churring.

\section{Data extraction}

Recordings from each territory were opened in Audacity version 2.1.3 and split into individual churrs, by using the cropping function, based on the corresponding behavioural notes. An individual churr ended when the male flew to a new song post or flew and returned to the same song post. The length of each churr (in seconds) and the number of pauses were obtained using Praat version 6.0.29 by looking for gaps a few seconds long within the individual churrs. The 'Filter(formula)...' function in Praat was used to filter out noise below $400 \mathrm{~Hz}$ and above $-3000 \mathrm{~Hz}$ in each individual churr, enabling background noise from traffic to be reduced. 
Churrs contained both major and minor phrases (Figure 1), which were distinguished by consistently higher and lower frequencies respectively. The mean length of the major and minor phrases was calculated in Praat by using the cursor to measure the length of each phrase and dividing the sum of the phrase lengths by the total number of phrases within each churr. The pulse rate of the major and minor phrases of the churr was calculated in Praat as pulses per second by measuring the mean number of seconds for ten pulses to occur across ten major and minor phrases chosen at random across the entire churr sample. The mean was then used as the pulses per second variable for each churr. Other parameters measured using the cursor included churr length (in seconds), number of pauses, number of major and minor phrases within the entire churr, maximum and minimum frequency $(\mathrm{Hz})$ of major and minor phrases, and the frequency bandwidth of major and minor phrases. After analysis at full length, recordings were cropped using Audacity to less than 120 seconds long to match the sample lengths used by Rebbeck et al. (2001) and analysed again by using Praat to extract the four variables that Rebbeck et al. used, to compare the relative success rates of individual identification between the two methods.

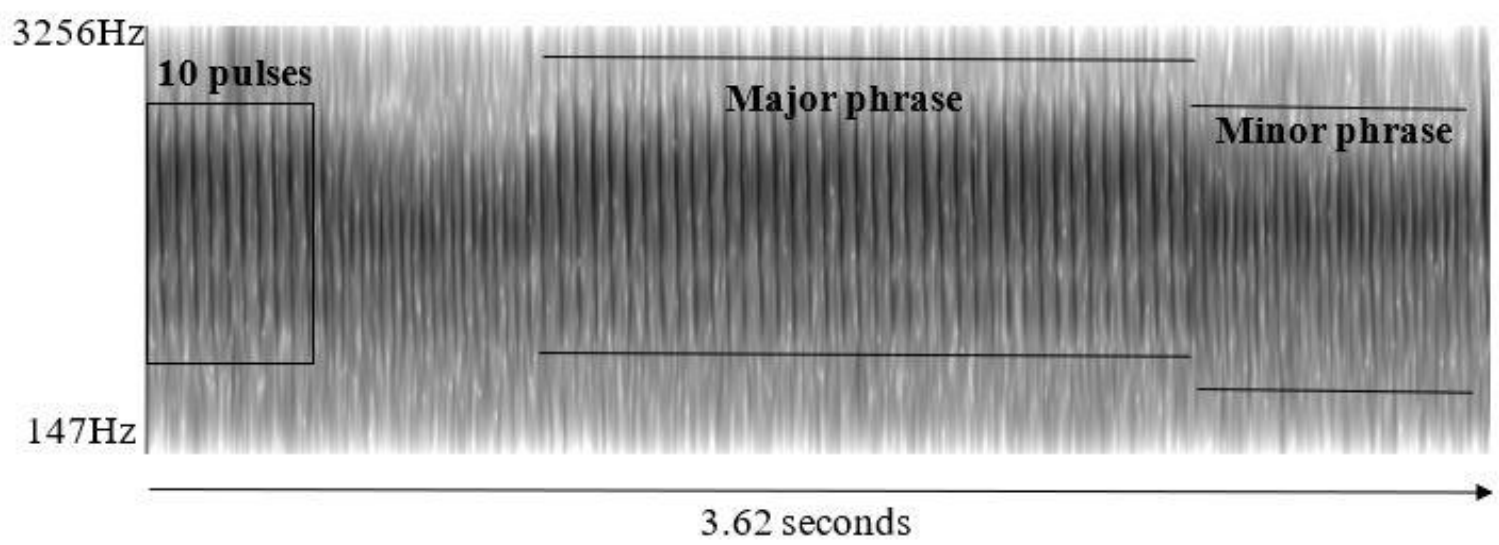

Figure 1. Typical sonogram of the churr of a male Nightjar labelled with the major and minor phrases and the identification of 10 pulses. 


\section{Data analysis}

Discriminant function analysis was performed using the same method as Rebbeck et al. (2001) to assess churr individuality based on the pulse rate and length of minor and major phrases. We then performed the analysis again using the full range of features we had measured. We used data gathered in 2016 to test whether we could identify males on the same territories in 2017 using the full range of measured features and following the methods of Rebbeck et al. (2001). We also used discriminant functions derived from the 2017 churr data to categorise churrs recorded in 2016. The 2016 dataset did not include a count of major phrases in each churr, so this variable was excluded from between-year analyses. The Euclidean distance (a measure of distance which is a metric of similarity between two points) was calculated manually between the group centroids of each territory, allowing a test of the assumption that vocalisations that were recorded on a particular territory were produced by the same males between years. Discriminant function analysis was performed in IBM SPSS Statistics 24 and group centroid and eigenvalues extracted. 


\section{Results}

\section{Male nightjar territory fidelity determined from ringing data}

Limited ringing data indicated that male nightjars returned to the same territories between years. Nine male nightjars that were marked and recaptured in Sherwood Pines Forest Park between 2004 and 2015 were recaptured on the same territory in at least two consecutive years. The average number of years of territory re-use was 3.3 years and one male nightjar returned to the same territory for eight consecutive years.

\section{Call characteristics}

In 2016 recordings of churrs were collected on 13 territories visited over 42 nights. Churring was heard from the resident male on each territory on all but six of these visits. From these recordings a total of 159 individual churr calls were identified and used in our analyses. Churring began between 9 minutes before and 46 minutes after civil twilight, with a mean initiation time of 19 minutes after twilight.

In 2017 recordings were collected on 11 territories, over 36 nights. Again, churring was heard from the resident male on all but six visits. From these recordings a total of 82 individual churr calls were identified and used in our analyses. Churring began between 6 minutes before and 51 minutes after civil twilight, with a mean initiation time of 22.5 minutes after twilight.

\section{Discrimination of individuals}

Discriminant function analysis was performed using only churrs of two minutes or less in length (as per Rebbeck et al. 2001) and only the pulse rate and phrase length variables, analysing data collected in 2016 and 2017 separately. Discriminant function analysis using leave-one-out classification correctly identified $45.1 \%$ of males from 2016 after cross- 
validation (49.0\% before cross-validation) and 73.5\% of males from 2017 after crossvalidation (79.5\% before cross-validation). The first two functions explained $92.7 \%$ of the variance in churrs for 2016, with the mean length of minor phrases and the pulse rate of major phrases being the most important predictor variables, while in 2017 the first two functions explained $88.9 \%$ of the variance, with the pulse rate of minor phrases and the pulse rate of major phrases being the most important predictor variables (Table 1). Figures 2 and 3 show the grouping of the calls by male using the first two discriminant functions for each year.

Table 1. Results of discriminant function analysis for classifying nightjar churrs to a male, based on the pulse rate and phrase length variables of churrs two minutes or less in length, for $2016(n=102)$ and $2017(n=68)$. The coefficients for the two functions which explained the greatest amount of variance in churrs are shown for the two variables which best predicted the identity of the male, along with the percentage of variance explained and eigenvalues for those functions.

\begin{tabular}{llll}
\hline Year & Variable & \multicolumn{2}{c}{ Coefficients } \\
& & Function 1 & Function 2 \\
\hline 2016 & Mean length of minor phrases (s) & 0.170 & -3.960 \\
& Rate of pulses in major phrases (pulses/s) & -0.881 & 0.119 \\
& Percentage of variance explained & 74.0 & 18.7 \\
& Eigenvalue & 1.81 & 0.458 \\
2017 & Rate of pulses in minor phrases (pulses/s) & 0.579 & -0.008 \\
& Rate of pulses in major phrases (pulses/s) & 0.612 & 0.054 \\
& Percentage of variance explained & 74.9 & 14.0 \\
& Eigenvalue & 9.288 & 1.736 \\
\hline
\end{tabular}




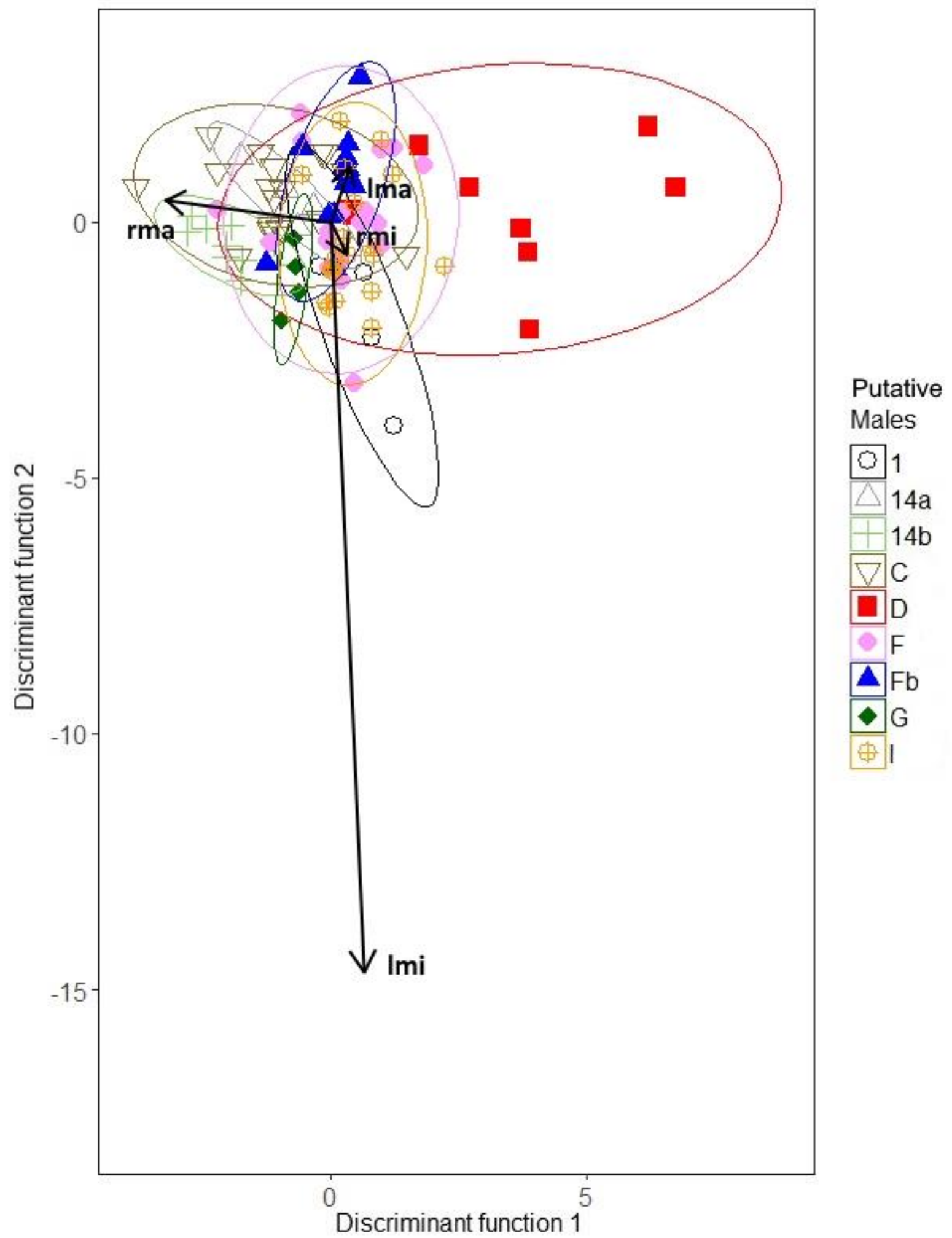

Figure 2. Linear discriminant analysis biplot of 2016 churr data using only phrase length and pulse rate variables and churrs of up to two minutes in length, with each male nightjar 
represented by a different shape. The axis of discriminant function 1 , for which the pulse rate of major phrases (pulses/second) is the greatest contributor, explains $74.0 \%$ of the variance. Vectors for the four most important predictor variables are labelled as follows: 1mi - mean length of minor phrases (seconds), lma - mean length of major phrases (seconds), rmi - pulse rate of minor phrases (pulses/second), rma - pulse rate of major phrases (pulses/second). Males were grouped by territory name and each territory is represented by a different symbol. Online version in colour. 


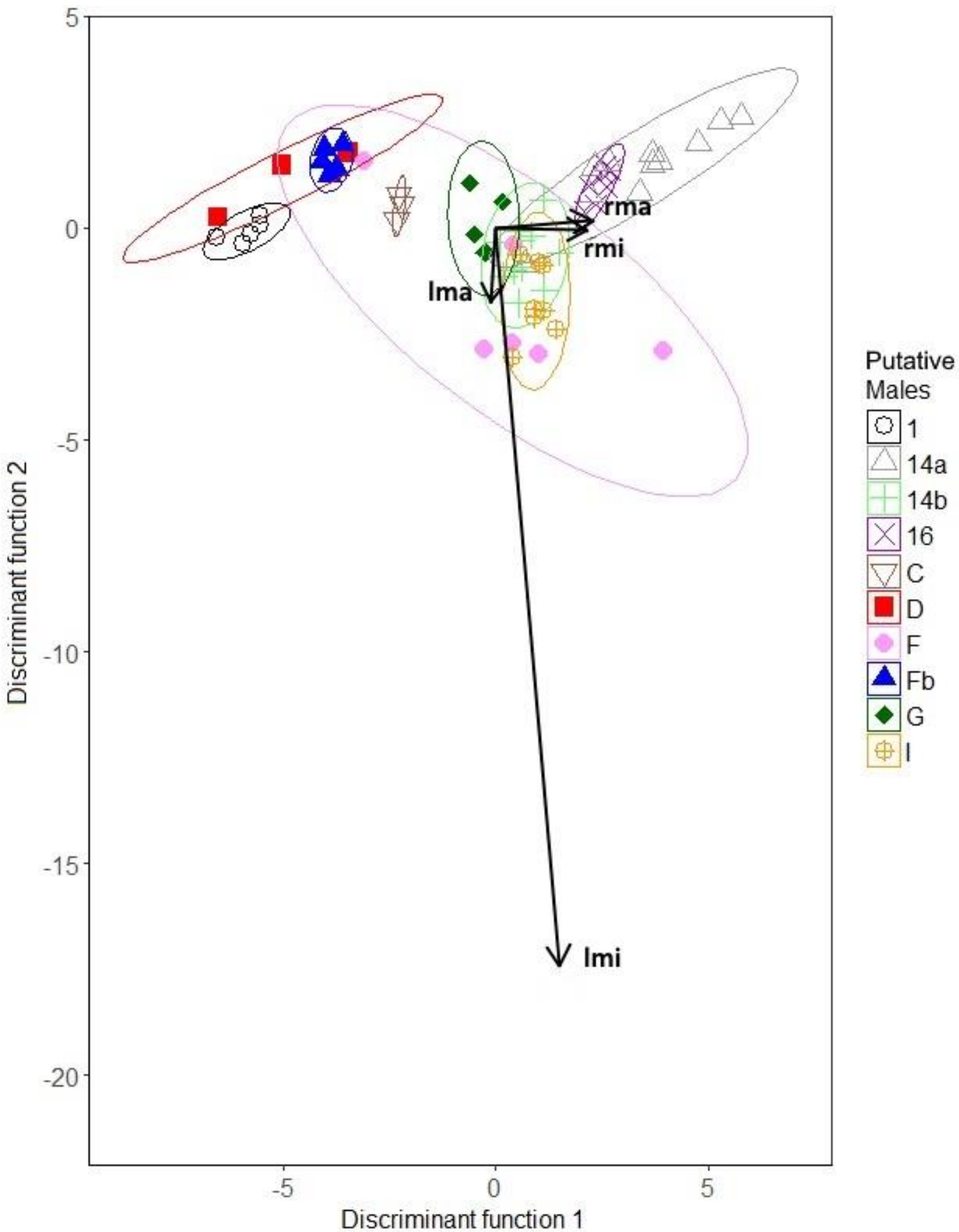

Figure 3. Linear discriminant analysis biplot of 2017 churr data using only phrase length and pulse rate variables and churrs of up to two minutes in length, with each male nightjar represented by a different shape symbol. The axis of discriminant function 1 , for which the pulse rate of major phrases (pulses/second) is the greatest contributor, explains $74.9 \%$ of the 
variance. Vectors for the four most important predictor variables are labelled as follows: 1mi mean length of minor phrases (seconds), lma - mean length of major phrases (seconds), rmipulse rate of minor phrases (pulses/second), rma - pulse rate of major phrases (pulses/second). Males were grouped by territory name and each territory is represented by a different symbol. Online version in colour.

Discriminant function analyses were then performed using the full length of recorded churrs and all variables (except for the bandwidth variables which failed tolerance tests for collinearity) for data collected in 2016 and 2017 separately. Discriminant function analysis using leave-one-out classification correctly identified 53.3\% of males from 2016 after crossvalidation (65.6\% before cross-validation) and $75 \%$ of males after cross-validation $(95.6 \%$ before cross-validation) for 2017. The first two functions explained $70.1 \%$ of the variance in churrs for 2016, with the mean length of major phrases and the pulse rate of major phrases being the most important predictor variables (Table 2, Figure 4), while for 2017 the first two functions explained $72.1 \%$ of the variance in churrs, with the mean length of minor phrases and the pulse rate of major phrases being the most important predictor variables (Table 2, Figure 5). 
Table 2. Results of discriminant function analysis for classifying nightjar churrs to a male, based on full length of recorded churrs and all variables measured, for data collected in 2016 $(\mathrm{n}=122)$ and $2017(\mathrm{n}=68)$. The coefficients for the two functions which explained the greatest amount of variance in churrs are shown for the two variables which best predicted the identity of the male, along with the percentage of variance explained and eigenvalues for those functions

\begin{tabular}{llll}
\hline Year & Variable & Coefficients & \\
& & Function 1 & Function 2 \\
\hline 2016 & Mean length of major phrases (s) & 0.122 & 0.007 \\
& Rate of pulses in major phrases (pulses s ${ }^{-1}$ ) & -0.816 & 0.480 \\
& Percentage of variance explained & 49.1 & 21.1 \\
& Eigenvalue & 2.444 & 1.049 \\
2017 & Mean length of minor phrases (s) & 1.386 & -1.093 \\
& Rate of pulses in major phrases (pulses s & \\
& Percentage of variance explained & 0.695 & 0.230 \\
& Eigenvalue & 44.6 & 27.5 \\
& & 10.042 & 6.182 \\
\hline
\end{tabular}




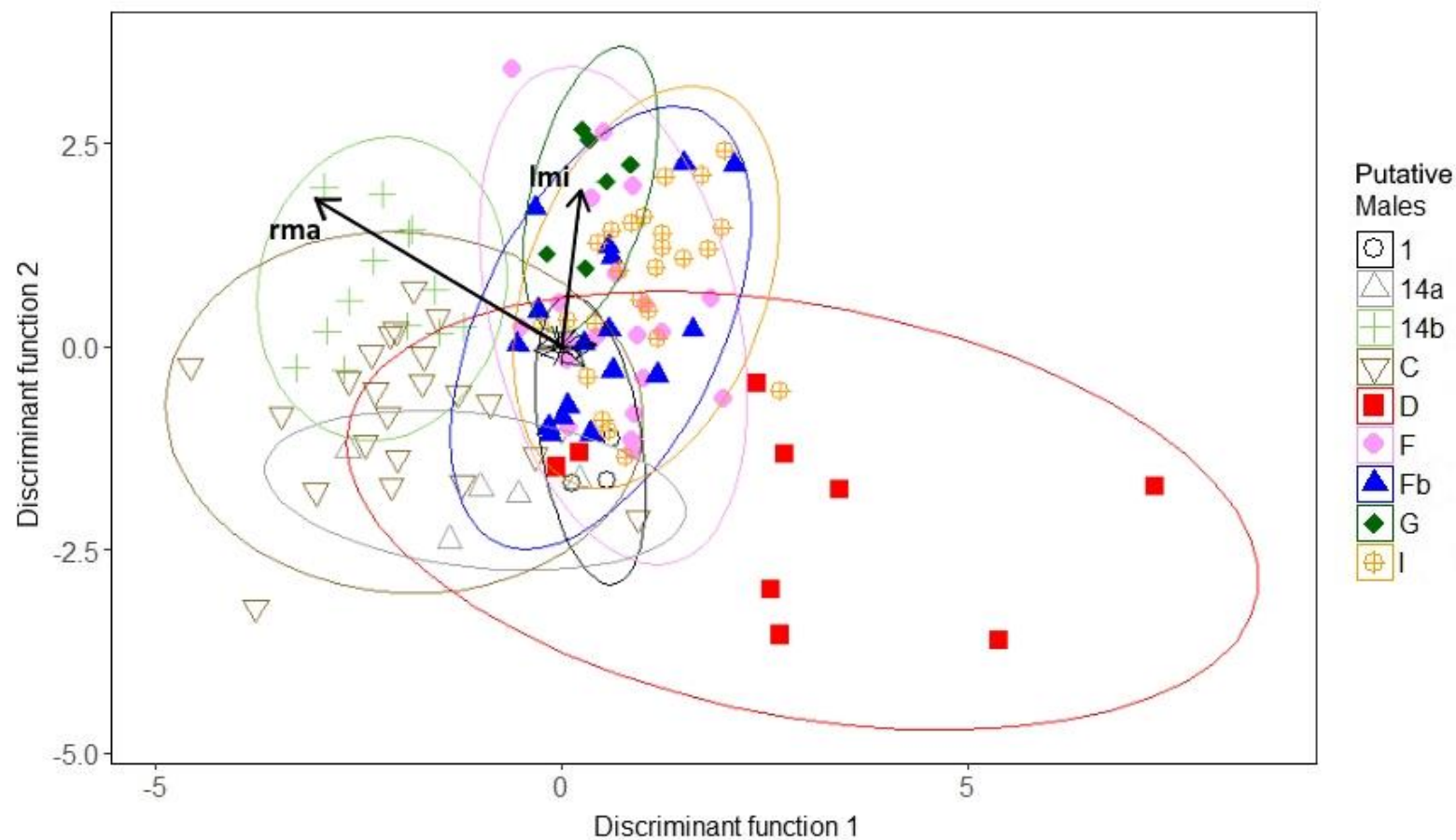

Figure 4. Linear discriminant analysis biplot of 2016 churr data with each male nightjar represented by a different shape symbol. The axis of discriminant function 1, for which the mean length of minor pulses (seconds) is the greatest contributor, explains $44.6 \%$ of the variance. Vectors for the most important predictor variable on each axis are labelled as follows: lmi - mean length of minor phrases (seconds), rma - pulse rate of major phrases (pulses/second). Males were grouped by territory name and each territory is represented by a different symbol. Online version in colour. 


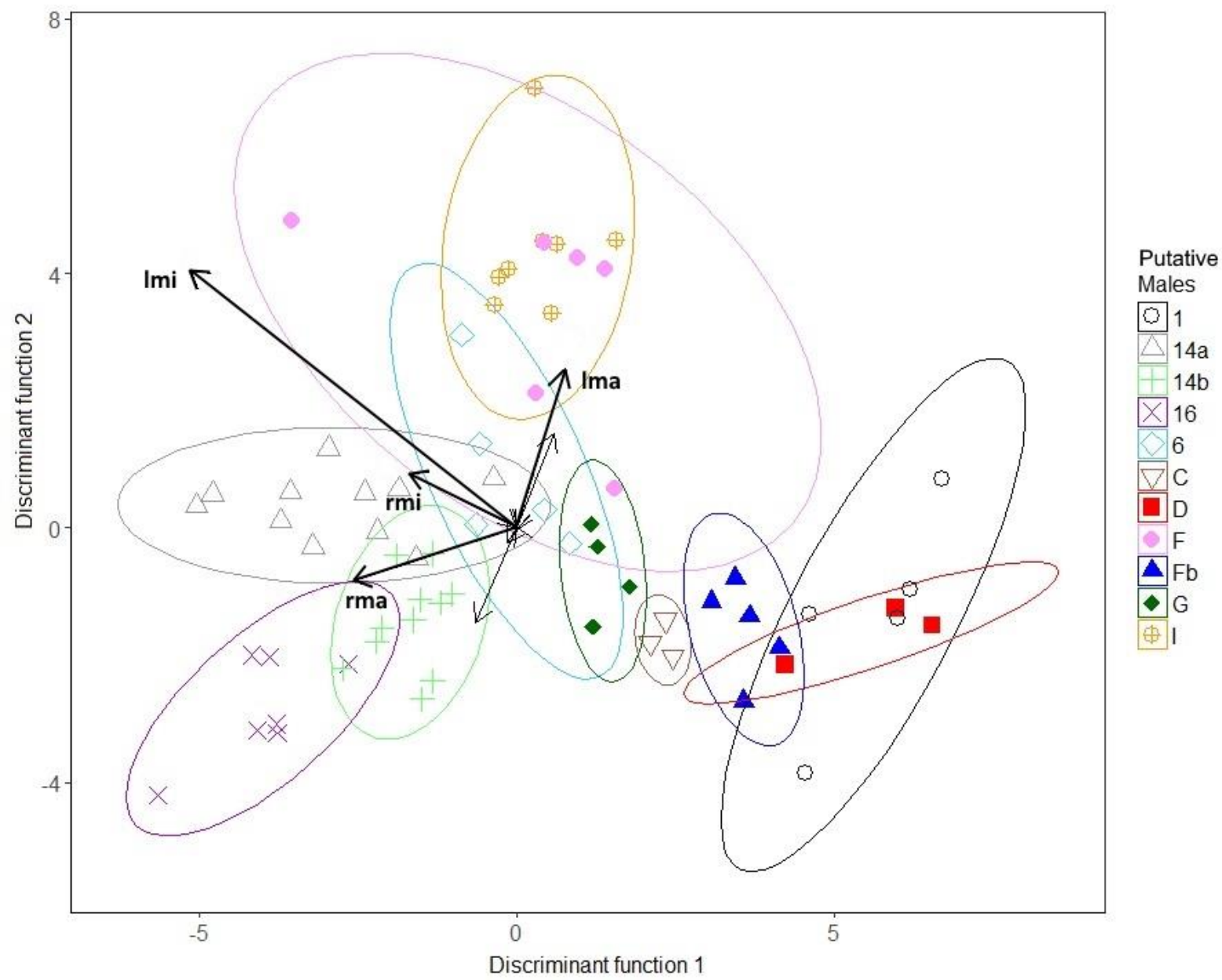

Figure 5. Linear discriminant analysis biplot of 2017 churr data with each male nightjar represented by a different shape symbol. The axis of discriminant function 1 , for which the mean length of minor pulses (seconds) is the greatest contributor, explains $44.6 \%$ of the variance. Vectors for the four most important predictor variables are labelled as follows: 1mi mean length of minor phrases (seconds), lma - mean length of major phrases (seconds), rmi pulse rate of minor phrases (pulses/second), rma - pulse rate of major phrases (pulses/second). Males were grouped by territory name and each territory is represented by a different symbol. Online version in colour.

\section{Between-year discrimination of individuals}

The Euclidean distances between discriminant function group centroids for a male occupying the same territory in 2016 and 2017 were in the range of $2.546-6.823$, with a mean distance 
of 4.5 , while the distances between males churring on different territories in 2017 were in a similar range of $2.908-6.978$, with a mean of 4.2 (Figure 6). The high degree of overlap in these ranges indicates that churrs recorded on the same territory in two consecutive years were not more similar than churrs of birds recorded on different territories within the same year. Discriminant function classification of churrs recorded in 2016 using the 2017 churr data as a training dataset classified just $20 \%$ of calls correctly ( 30 of 147 churrs). Of the 30 calls correctly classified, 27 of them were recorded in three territories, with $50 \%$ of churrs recorded on territories I and $\mathrm{Fb}$ in 2016 being correctly classified and 33\% from territory 14a.

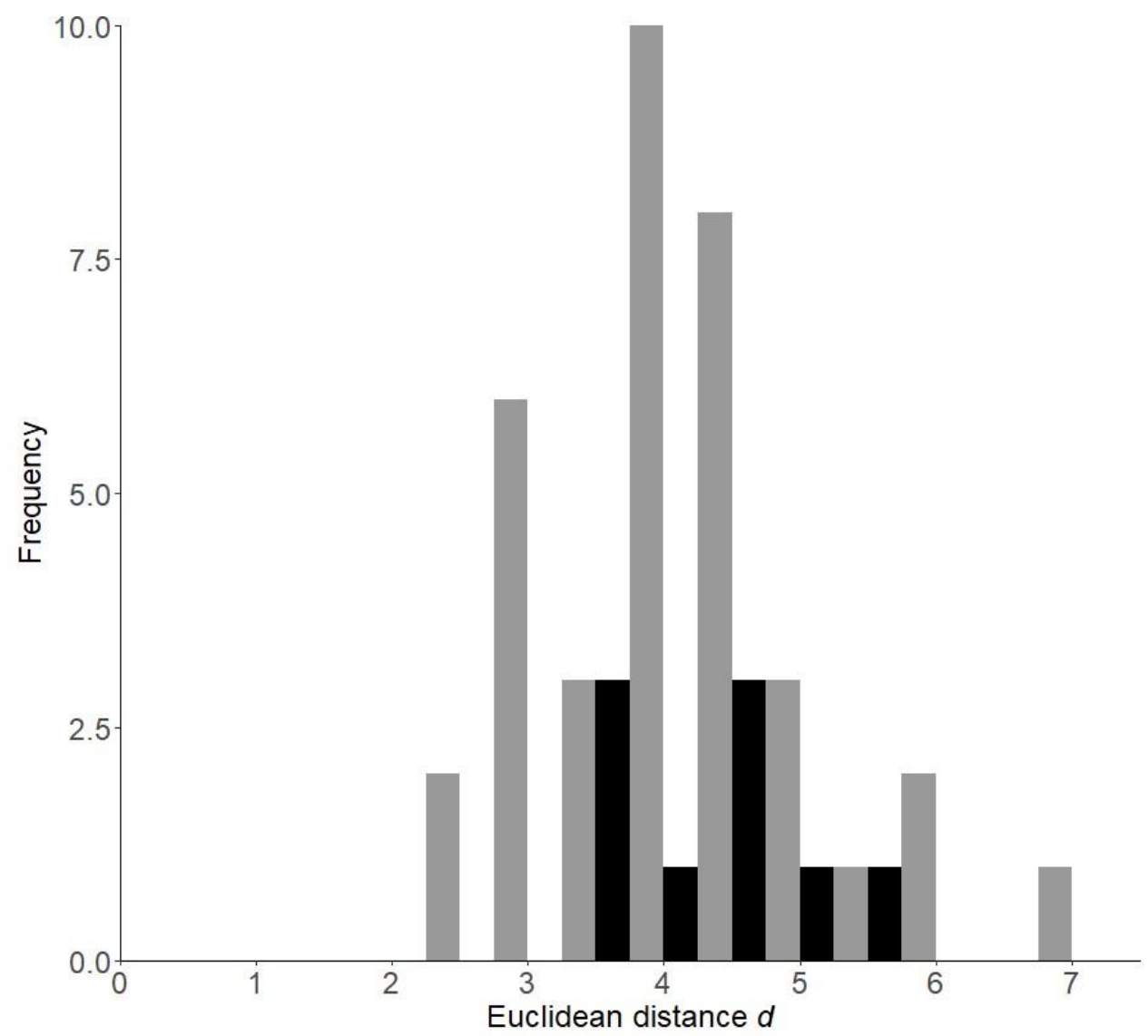

Figure 6. The frequency of occurrence of the Euclidean distance $d$ between dyads of discriminant function group centroids for the same territory between years, comparing churrs recorded in 2016 and in 2017, and different territories in the same year. The high degree of overlap in the ranges of the Euclidean distance indicates that churrs recorded at the same 
territory across two years were no more similar than churrs recorded at different territories within the same year.

\section{Summary}

To determine the efficacy of acoustic monitoring between years to assess site fidelity, we used site fidelity that was acquired through ringing data and compared those data to our acoustic data that was acquired via using putative individuals on known territories. Given the large disparity between these two sets of results and the unlikelihood of an $80 \%$ territory replacement rate between years, we conclude that males change their vocalisations between years, therefore limiting robust acoustic monitoring to within-year analyses. 


\section{Discussion}

Discriminant function analysis of male nightjar calls using the same parameters as Rebbeck et al. (2001), including pulse rates and phrase lengths for minor and major phrases, produced much lower successful identification rates with our population of nightjars than in the original study. Whilst Rebbeck found that $98.5 \%$ of males were correctly classified, only $45.1 \%$ of males in 2016 and $73.5 \%$ of males in 2017 were correctly classified in our study. The two most important parameters for identifying individuals in Rebbeck's population were major and minor pulse rates, which is also the case for our 2017 population; however, in 2016 we found that the mean length of the minor phrase and the major pulse rate were the best determinants of individuality. The inconsistencies in the importance of parameters in discriminating between individuals between the two years in this study and between the present study and Rebbeck et al.'s (2001) overall, indicate that restricting variables to only a few types may give a false impression of the variables requiring measurement in different populations and years to robustly acoustically identify individuals over time.

We tested whether the addition of extra parameters (increasing the total from four to 13) and use of whole churrs would improve our ability to discriminate between individuals. We found that the percentage of correctly classified calls increased to a maximum of $75 \%$; however, this is still relatively poor for identification purposes compared to other studies (eg: Grava et al. 2008; Li et al. 2017). Similar studies into vocal individuality of birds have also found discrepancies between how effectively call parameters can be used to distinguish between individuals of the same species. For example, a study into the buff-throated woodcreeper Xiphorhynchus guttatus used six parameters to correctly assign $100 \%$ of songs for three individual birds (Moseley and Wiley 2013); however, calls from three other individuals were misidentified as close-neighbouring birds which was attributed to the close proximity of the birds and calls temporally overlapping. Nightjar males occasionally overlap 
their calls, but we did not include any recordings that included more than one male in our analyses and can thus exclude this problem in the present study. The tendency of the males of many bird species to overlap their calls in territorial interactions (e.g. Mennill and Ratcliffe, 2004; Vehrencamp et al. 2007) can negatively impact the effectiveness of vocal discrimination as a census method.

The between-year call analysis in both studies produced low percentages of reliably classified calls, with both Rebbeck et al. (2001) and the present study finding significant overlap between same-bird data from different years and different-bird data from the same year. Only $20 \%$ of calls from the 2016 dataset were correctly classified by discriminant function analysis using the 2017 dataset as training data, with three territories accounting for 27 out of 30 of the correctly classified calls. At these territories, only $50 \%$ of calls were correctly classified across years, demonstrating that recordings from the same individuals did not always produce the same results and thus vocalisations cannot necessarily be used reliably on their own to monitor individual return rates to territories. Our limited ringing data confirmed that some male nightjars return to the same territorial location each year, for as long as eight consecutive years. Female nightjars are thought to change territories and mates each year (Cramp 1985), while males are thought to return to the same sites approximately two weeks in advance of the migrating females and churr to advertise their presence. It is therefore unlikely that there was an $80 \%$ replacement rate of individual males between years; rather, vocal changes in individuals between years are more likely. This means that acoustic monitoring in the absence of other supporting data may not be the most accurate stand-alone census method for long-term monitoring of bird populations.

Despite male nightjars being known for their high site fidelity (Berry 1979; Jackson 1985; Poulin et al. 1996), the low percentage of calls classified as the same males on the same territories could also be explained by high mortality rates between years, particularly 
during migration, when mortality rates in some species can be six times higher than during stationary periods (Klaassen et al. 2013). Although this nightjar population has declined over the last decade (Lowe et al. 2014), our survey data does not support such high mortality between years, therefore misclassification of returned male's calls due to changing vocal characteristics seems the more likely scenario to explain our results.

Although several recent studies have demonstrated stability in vocal individuality of non-passerine species over multiple years (e.g. Galeotti and Pavan 1991; González-García et al. 2017), others, like ours, have not been successful in re-identifying birds over multiple years (e.g. Zdenek et al. 2017). Some studies have found that successful re-identification declines gradually over time. For example, Odom (2013) was able to categorise the calls of great horned owls, Bubo virginianus with $100 \%$ accuracy over a single session, $83 \%$ accuracy over the season and only $60 \%$ accuracy over two seasons. As in our study, birds in Odum's (2013) study were unmarked, so the reduction in correct categorisation over time may have been due to change in territory occupancy. Alternatively, the same birds may be present, but their call characteristics may have changed. Vocalisations can be very plastic and alter in response to age, condition, environment, motivation and social conditions (Walcott et al. 2006; Ellis 2008; Vehrencamp et al. 2013; Humphries et al. 2016). Some performance variables, such as pulse rate and bandwidth, can be dependent on the motivational state of the male at the time of each call (DuBois et al. 2009).

Nightjars churr to attract a new mate each season (Cramp 1985), so there may not be a great adaptive advantage to retaining stability in call features over longer periods than a single season. In Rebbeck et al.'s (2001) study, ten of the 21 birds were only recorded on a single morning or night. Of the eleven birds recorded twice or more, three had their recordings separated by less than a week. The longest period over which recordings were made was six weeks, and this was only for two birds. In contrast, we recorded from each of 
our territories on three separate evenings, with recordings for all birds spread over a sevenweek period in 2017 and over eight weeks in 2016. Variation in the characteristics of the nightjar's call over time may therefore account for the higher percentage of correct classifications achieved by Rebbeck et al. (2001). Our results indicate that long-term vocal identification is not possible in nightjars, but to confirm this, this study should be repeated with marked birds.

Advances in audio recording technology promise to improve the quantity and type of data that can be gathered by acoustic monitoring in future. Arrays of automated recorders can be used to gather data over longer periods of time and triangulate the position of calling birds (McGregor et al. 1997; Kirschel et al. 2011). This can allow monitoring or tracking of birds in dense undergrowth or at night (Mennill 2011; Frommolt and Tauchert 2014). The continuous monitoring these devices can provide increases the chances of identifying rare or elusive species (Jahn et al. 2017). Sound recognisers can be used to scan recorded soundscapes for calls of a particular bird species, making analysis easier. Zwart et al. (2014) compared the effectiveness of automated bio-acoustic recorders and associated classification software with traditional human surveying techniques in detecting the presence of nightjars and found that the automated recorders detected nightjars in 19 of 22 survey periods compared to six of 22 for human surveyors. While these advances may allow us to more easily detect the presence of nightjars on a territory, based on our results, they would not be able to reliably identify and track individuals over time.

Peake et al. (1998) found that by adding features of fine temporal structure, such as pulse to pulse duration, to their analysis they were able to improve classification from $87 \%$ to $100 \%$. Fine temporal structure analysis may also yield improvements in the classification of nightjar calls, potentially allowing more successful discrimination between individuals; however, very high-quality recordings, with minimal to no background noise, would need to 
be obtained in order to utilise fine scale parameters and this is inherently difficult when working in natural environments.

Vocal discrimination may be useful for conducting a census of nightjars within a compact site where each male on a territory can be recorded within a very short time frame. Our results indicate that vocal individuality as a monitoring technique is not currently suitable for use in longer-term studies, as variation in call parameters over time may cause misidentification, possibly leading to overcounting which could have negative consequences for nightjar conservation. We recommend using traditional field techniques of mark and recapture and that field workers develop a deep knowledge of both their site and population if anything more than presence/absence data is required, in order to understand population demographics over time.

Acknowledgements: We would like to thank Ann Ward and the past and present members of Birklands Ringing Group for their tireless fieldwork to monitor the nightjars of Sherwood Pines. We thank the Forestry Commission for their support and permission to use the land. Thanks to Francis Gilbert, Andrew MacColl and two reviewers for constructive comments on the manuscript. This work was funded by Birklands Ringing Group and the University of Nottingham. 


\section{References}

Axelrod R, Hamilton WD. 1981. The evolution of cooperation. Science. 211:1390-1396.

Berry, R. 1979. Nightjar habitats and breeding in East Anglia. Brit. Birds. 72: 207-218.

Brandes TS. 2008. Automated sound recording and analysis techniques for bird surveys and conservation. Bird Conserv Int. 18:S163-S173.

Budka M, Osiejuk TS. 2013. Neighbour-stranger call discrimination in a nocturnal rail species, the Corncrake Crex crex. J Ornithol. 154:685-694.

Budka M, Wojas L, Osiejuk TS. 2015. Is it possible to acoustically identify individuals within a population? J Ornithol. 156:481-488.

Cadbury CJ. 1981. Nightjar census methods. Bird Study. 28:1-4.

Charrier I, Jouventin P, Mathevon N, Aubin T. 2001. Individual identity coding depends on call type in the South Polar skua Catharacta maccormicki. Polar Biology. 24:378-382.

Colgan PW. 1983. Comparative social recognition. New York (NY): Wiley.

Cramp S. 1985. Handbook of Europe, the Middle East and North Africa: the birds of the Western Palearctic, volume IV: terns and woodpeckers. Oxford (UK): Oxford University Press.

Cresswell B, Edwards D. 2013. Geolocators reveal wintering areas of European Nightjar (Caprimulgus europaeus). Bird Study. 60:77-86.

del Hoyo J, Elliot A, Sargatal J. 1999. Handbook of the birds of the world. Barcelona: Lynx.

DuBois AL, Nowicki S, Searcy WA. 2009. Swamp sparrows modulate vocal performance in an aggressive context. Biol Lett. 5:163-165.

Eaton M, Aebischer N, Brown A, Hearn R, Lock L, Musgrove A, Noble D, Stroud D, Gregory R. 2015. Birds of Conservation Concern 4: the population status of birds in the UK, Channel Islands and Isle of Man. Brit. Birds. 108:708-746.

Ellis, J. 2008. Decay of apparent individual distinctiveness in the begging calls of adult female White-throated magpie-jays. Condor 110: 648-657.

Falls JB. 1982. Individual recognition by sound in birds. In: Kroodsma DE, Miller EH, editors. Acoustic communication in birds. Volume 2: Song learning and its consequences. New York (NY): Academic Press; p. 237-278.

Frommolt KH, Tauchert KH. 2014. Applying bioacoustic methods for long-term monitoring of a nocturnal wetland bird. Ecol Inform. 21:4-12.

Galeotti P, Pavan G. 1991. Individual recognition of male tawny owls (Strix aluco) using spectrograms of their territorial calls. Ethol Ecol Evol. 3:113-126. 
Gilbert, G, McGregor, PK, Tyler, G. 1994. Vocal Individuality as a Census Tool: Practical Considerations Illustrated by a Study of Two Rare Species. J Field Ornithol. 65:33548.

Gómez-Catasús J, Garza V, Traba J. 2018. Wind farms affect the occurrence, abundance and population trends of small passerine birds: the case of the Dupont's lark. J Appl Ecol. 55(4):2033-2042.

González-García F, Sosa-López JR, Ornelas JF, Jordano P, Rico-Gray V, Urios Moliner V. 2017. Individual variation in the booming calls of captive Horned Guans (Oreophasis derbianus): an endangered Neotropical mountain bird. Bioacoustics. 26:185-198.

Grava T, Mathevon N, Place E, Balluet P. 2008. Individual acoustic monitoring of the European Eagle Owl Bubo bubo. Ibis. 150:279-287.

Halpin ZT. 1991. Kin recognition cues of vertebrates. In: Hepper PG, editor. Kin recognition. Cambridge (UK): Cambridge University Press; p. 220-258.

Humphries DJ, Finch FM, Bell MB, Ridley AR. 2016. Vocal cues to identity: pied babblers produce individually distinct but not stable loud calls. Ethology. 122:609-619.

Jackson HD. 1985. Aspects of the breeding biology of the Fierynecked Nightjar. Ostrich. 56:263-276.

Jahn O, Ganchev TD, Marques MI, Schuchmann KL. 2017. Automated sound recognition provides insights into the behavioral ecology of a tropical bird. PloS one. 12:e0169041.

Jiguet F, Williamson T. 2010 Estimating local population size of the European Nightjar Caprimulgus europaeus using territory capture-recapture models. Bird Study. 57:509514.

Kirschel AN, Cody ML, Harlow ZT, Promponas VJ, Vallejo EE, Taylor CE. 2011. Territorial dynamics of Mexican Ant-thrushes Formicarius moniliger revealed by individual recognition of their songs. Ibis. 153:255-268.

Klaassen RHG, Hake M, Strandberg R, Koks BJ, Trierweiler C, Exo KM, Bairlein F, Alerstam T. 2013. When and where does mortality occur in migratory birds? Direct evidence from long-term satellite tracking of raptors. J Anim Ecol. 83(1):176-184.

Klenova AV, Zubakin VA, Zubakina EV. 2011. Individuality in trumpet calls of the crested auklet (Aethia cristatella), a highly social species. Moscow Univ Biol Sci Bull. 66: 114. 
Langston RHW, Wotton SR, Conway GJ, Wright LJ, Mallord JW, Currie F.A., Drewitt AL, Grice PV, Hoccom DG, Symes N. 2007. Nightjar Caprimulgus europaeus and Woodlark Lullula arborea - recovering species in Britain? Ibis. 149:250-260.

Lengagne T. 2001. Temporal stability in the individual features in the calls of eagle owls (Bubo bubo). Behaviour. 138:1407-1419.

Li Y, Xia C, Lloyd H, Li D, Zhang Y. 2017. Identification of vocal individuality in male cuckoos using different analytical techniques. Avian Res. 8:21.

Lowe A, Rogers A, Durrant K. 2014. Effect of human disturbance on long-term habitat use and breeding success of the European Nightjar, Caprimulgus europaeus. ACE. 9:6.

Magrath RD, Haff TM, Horn AG, Leonard ML. 2010. Chapter 6 - calling in the face of danger: predation risk and acoustic communication by parent birds and their offspring. Adv Study Behav. 41:187-253.

McGregor PK, Dabelsteen T, Clark CW, Bower JL, Holland J. 1997. Accuracy of a passive acoustic location system: empirical studies in terrestrial habitats. Ethol Ecol Evol. 9:269-286.

McGregor PK, Peake TM. 1998. The role of individual identification in conservation biology. In: Caro T, editor. Behavioral Ecology and Conservation Biology. Oxford (UK): Oxford University Press; p. 31-55.

Mennill DJ. 2011. Individual distinctiveness in avian vocalizations and the spatial monitoring of behaviour. Ibis. 153:235-238.

Mennill DJ, Ratcliffe LM. 2004. Overlapping and matching in the song contests of blackcapped chickadees. Anim Behav 67:441-450.

Moseley DL, Wiley RH. 2013. Individual differences in the vocalizations of the buff-throated woodcreeper (Xiphorhynchus guttatus), a suboscine bird of neotropical forests. Behaviour. 150:1107-1128.

Odom KJ, Slaght JC, Gutiérrez RJ. 2013. Distinctiveness in the territorial calls of great horned owls within and among years. J Raptor Res. 47:21-30.

Ota N, Soma M. 2014. Age-dependent song changes in a closed-ended vocal learner: elevation of song performance after song crystallization. J Avian Biol. 45(6):566-573.

Parra M, Dalisio AC, Jensen WE, Parker TH. 2017. Male territorial aggression does not drive conformity to local vocal culture in a passerine bird. Ethology. 123(11):800-810.

Peake TM, McGregor PK, Smith KW, Tyler G, Gilbert G, Green RE. 1998. Individuality in Corncrake Crex crex vocalizations. Ibis. 140:120-127. 
Poulin RG, Grindal SD, Brigham RM. 1996. Common Nighthawk (Chordeiles minor). In: Poole A, Gill F, editors. The Birds of North America. Washington (WA): American Ornithologists' Union; p. 213.

Rebbeck M, Corrick R, Eaglestone B, Stainton C. 2001. Recognition of individual European Nightjars Caprimulgus europaeus from their song. Ibis. 143:468-475.

Tella JL, Vögeli M, Serrano D, Carrete, M. 2005. Current status of the threatened Dupont's lark Chersophilus duponti in Spain: overestimation, decline, and extinction of local populations. Oryx. 39(1):90-94.

Terry AM, Peake TM, McGregor PK. 2005. The role of vocal individuality in conservation. Front Zool. 2:10.

Vargas-Castro LE, Sandoval L, Searcy WA. 2017. Eavesdropping avoidance and sound propagation: the acoustic structure of soft song. Animal Behav. 134:113-121.

Vehrencamp SL, Hall ML, Bohman ER, Depeine CD, Dalziell AH. 2007. Song matching, overlapping, and switching in the banded wren: the sender's perspective. Behav Ecol 18:849-859.

Vehrencamp, SL., Yantachka, J., Hall, ML., de Kort, SR. 2013. Trill performance components vary with age, season, and motivation in the banded wren. Behav. Ecol. Sociobiol. 67:409-419.

Walcott, C., Mager, JN., Piper, W. 2006. Changing territories, changing tunes: male loons, Gavia immer, change their vocalizations when they change territories. Anim. Behav. 71:673-683.

White GC, Burnham KP. 1999. Program MARK: survival estimation from populations of marked animals. Bird Study. 46(S1):S120-S139.

Zdenek CN, Heinsohn R, Langmore NE. 2017. Vocal individuality, but not stability, in wild palm cockatoos (Probosciger aterrimus). Bioacoustics. 27:27-42.

Zwart MC, Baker A, McGowan PJ, Whittingham MJ. 2014. The use of automated bioacoustic recorders to replace human wildlife surveys: an example using nightjars. PloS one. 9:e102770. 